\title{
sciendo
}

This journal provides immediate open access to its content under the Creative Commons BY 4.0 license.. Authors who publish with this journal retain all copyrights and agree to the terms of the above-mentioned CC BY 4.0 license

\section{RECONCILIATION BETWEEN THE VICTIM AND THE PERPETRATOR-RESTORATIVE JUSTICE}

\author{
Albana Aliu \\ PhD. Candidate at Criminal Law, Faculty of Law, \\ South East European University, Tetovo, North Macedonia \\ aa29732@seeu.edu.mk \\ Besa Arifi \\ Full Professor, Faculty of Law, \\ South East European University, Tetovo, North Macedonia \\ b.arifi@seeu.edu.mk
}

\begin{abstract}
The purpose of this research is to study and address the relation between the perpetrator and the victim, in particular the way it is regulated in the Republic of Kosovo by comparing it with the regulation in other countries. A long time ago criminal law in its institutes has paid attention only to the perpetrator, trying to guarantee his fundamental rights, it is enough to stop at the institute of presumption of innocence and many other institutes and we can see how importance criminal law and in particular criminal procedure has paid to the perpetrator, and on the other hand the victim has always remained in the shadows.

Therefore, today we find it reasonable to address this issue, to find out from which period criminal law and authors of criminal law turn their heads towards the victim, to find out what is the position of the victim in society today, what steps have been taken in legal terms and also special attention will be paid precisely to restorative justice as a key point for the realization of the rights of the victim, the compensation of the damage and the restoration of balance and the establishment of relations in society. And it is quite important that in addition
\end{abstract}


to the relations that perpetrators have with victims, we also try to understand the historical course of restorative justice and this way to make an analysis of the position of the victim and the perpetrator over the decades.

Keywords: Restorative justice, victim, perpetrator, crime, mediation.

\section{INTRODUCTION}

The rapid development of society has imposed the need to find tools and methods for successfully combating new forms of crime. This development has imposed the need for an adequate response of society to the perpetrator of criminal offenses and greater involvement of victims in these processes, as they are the first persons affected by the consequences of the criminal offense. The society's response to crime has changed over time and continues to change and adapt to change and overall social development. Recently, the justice system was driven by the need for society to punish perpetrators of criminal offenses, with the aim of punishing them for the crime committed and preventing them from committing such offenses in the future, or similar, but now those intentions have changed, because now the intentions of the sentence are not only those that were mentioned, which were focused only on the perpetrator, but, now they also focus on the victim, the community and their compensation for losses and damages caused.

The criminal offense is no longer just a violation committed by the perpetrator against the interests of the state, but is a violation of the rights of one person by another person, respectively "The criminal offense is a violation of the rights of one person by another person, more than a violation against the state".

Therefore what interests us today is to deal with how this issue was and is regulated by the legislation in force in the Republic of Kosovo, to make a comparison of how this issue is regulated in other countries and to give answer some questions such as: what is the position of the victim today in the procedure, what is the purpose of punishment in contemporary societies, has society changed its approach to the injured party, what are the benefits of applying restorative justice. 


\section{THE FIRST BEGINNINGS OF RESTORATIVE JUSTICE}

The first forms of restorative justice have been applied since the first societies. Indigenous peoples, such as the Aboriginal, Inuit, and American Indians, have applied Family Group Conferences and Circles (Weitekamp, 1999). These traditions have a very long history and are rooted in the customs and religions of the people. The community has resolved those conflicts that have arisen between individuals, through various forms of reaction, and, as the most common were those of mediation and restitution (return to the previous state). These forms of reaction have been dominant until the twentieth century.

The idea of developing restorative justice, in the 70 s of the $\mathrm{XX}$ century, greatly contributed to the ideas of the formal justice movement, and, especially, the concept of "Conflict as Property", which was developed at the time by Nils Christie (Tulumovic, 2014). The essence of the concept of justice it is formal to limit the role of the state in resolving conflicts and to give priority to resolving those conflicts, as well as to maximize the participation of all stakeholders.

In many sources, the term "Restorative Justice" is said that is appeared in the first half of the ninetieth century. According to the data, this term was first used by the American Albert Eglash, in 1977 (Van Ness, 2002). Meanwhile, the initiators were Mark Umberi and Russ Jmmarigeoni. Their goal was to bring reconciliation of the victim with the perpetrators through restorative justice. This reconciliation program was first implemented in Ontario and required mediator engagement. In principle, this program was implemented in three steps, as:

1. The step of crime analysis with the victim and the perpetrator of the crime

2. The step of getting acquainted with the subscription program

3. The appeal step for awareness and realization of program determinations

Restorative justice is also based on Bible principles. The conciliation program was dedicated to nonviolent cases, usually property rights violations. It is very difficult for this program to be implemented in cases of serious crime. Crime is considered a conflict between the individual, which is reflected in society and the state. The purpose of the program is to reconcile the parties and compensate the damage. However, in addition to the participants, it is necessary to engage the society from the close circle of actors, to implement this justice in practice, through mediation, compensating the victim. The restorative justice process consists of:

Pre-mediation phase, which consists of: 

a) contact with the parties
b) their consent to the engagement of the mediator
c) arranging their meeting

The mediation phase which consists of:

a) agreement and reconciliation

b) termination and dispute, as symbolic compensation

c) the contract for compensation of damage

The result tracking phase, which consists of:

a) reintegration of the perpetrator in the community and re-socialization as well

b) moral and material satisfaction for the victim (Adzajlic-Dedovic, 2007).

Restorative justice was a response to the traditional criminal justice system and a point that the society could not continue, with the system in which the necessity of punishment is seen through the judicial process and the need to rehabilitate the perpetrator through the help of society, but now, through this justice, it must evolve and find a new philosophy, forms and methods through which the victim would be included, as the first and main factor, which is attacked by the evil of the perpetrator and strengthen its role in resolving many issues, which can be resolved even without the implementation of the traditional criminal justice system. The dissatisfaction expressed long ago in the traditional justice system, would be eliminated by applying restorative justice in practice, and, with this, the high crime rate would be reduced, because the position of the injured party would be re-evaluated, turning this into a person leading and putting the state in a secondary position, because the need to compensate the consequences pushes the injured party more than the state, to resolve a concrete issue.

Elements of restorative justice were also contained in Roman law. In particular, those elements can be observed in the part where it is about Reperatio Damni (Compensation) in the obligations, where, among other things, it is said that "the right to seek compensation also have the people which their protected values were damaged with the illegal actions of the delinquents" and that is always based on the rules for the responsibility of the delinquents, due to the illegal damages.

Actions that violated or damaged the protected legal values of persons, in Roman law were considered as illegal human acts or delicta, and all of them were divided into: 
1. Delicta Publica or Crimina or criminal offenses, they were illegal actions that in Roman law were sanctioned with any physical harm to the perpetrator of the criminal offense or with a fine in money, which had to be paid to the state treasury.

2. Private delicta, were those illegal actions which violated the protected legal interests of the Roman citizen, which were sanctioned either with the compensation of the damage caused or with the multiple compensation of the damage caused (Krasniqi, 2015).

Alternative conflict resolution (informal) and restorative justice cannot now be set aside, as they aim to define the conflict and protect the rights of both parties. Restorative justice itself seeks to extend the issue beyond the legal aspect, focusing, especially on basic relationships (Braithwaite, 2002)

\section{RESTORATIVE JUSTICE AND THE CRIMINAL LEGAL SYSTEM OF THE REPUBLIC OF KOSOVO}

The practice of restorative justice in Kosovo, as well as in Albania, has been evident in the ancient past and it continues to be present today. This is confirmed by the Kanun of Lekë Dukagjini and the legal provisions that have followed until today. In articles 667-682 of this Kanun it is written about the institute of conciliation and that of mediation. The most common feature of Albanian customary law from north to south is the use of the institute of forgiveness and reconciliation to limit blood feuds.

Various conflicts between the parties today in the Republic of Kosovo, in addition to mediation, are resolved through other alternative procedures provided by applicable legal provisions, such as: Temporary suspension of proceedings; Conditions when follow-up is not mandatory; Plea agreement; Release from punishment, etc. Then, the diversion from article 184 of Code no. 04 / L-123 of the criminal procedure of the Republic of Kosovo when such procedure or diversion is in accordance with the duties and competencies of the state prosecutor from article 49 of this Code and diversity measures (in criminal proceedings initiated against juveniles) etc. (Code of Criminal Procedure in Republic of Kosovo, no.04/L-123). All these procedures through which today in the Republic of Kosovo the conflicts between the parties are resolved, are supported also in international documents, such as: the European Convention on Human Rights; Charter of Fundamental Rights of the European Union. 


\section{Restorative justice and its place in the legislation of the republic of kosovo}

As in many legislations of contemporary states, the legislation of the Republic of Kosovo today contains elements of restorative justice. These elements have been introduced into our legislation since 1999 as our criminal justice system has undergone numerous reforms both in legislation and in other state and social spheres. There were elements of this (restorative) justice in the criminal codes (both for adults and juveniles) and those of the criminal procedure which were in force from 2013 until today. We find those elements of restorative justice today in the new Criminal Code and that of juveniles of the Republic of Kosovo which in Kosovo have begun to be implemented from the end of the first half of 2019.

These elements are also present in the Draft of new Criminal Procedure Code which is expected to be approved very soon by the Assembly of the Republic of Kosovo. Provisions that have elements of restorative justice are found in all these codes and their place is such as all participants in criminal proceedings can easily see that they can solve their cases not only through the traditional way but also through other procedures, both restorative ones, such as: Mediation procedure, and through alternative ones, such as: Temporary suspension of the procedure; Conditions when follow-up is not mandatory; Plea agreement; Release from punishment, etc. Then, the diversion from article 184 of Code no. 04 / L-123 of the Criminal Procedure of the Republic of Kosovo when such procedure or diversion is in accordance with the duties and competencies of the state prosecutor from article 49 of this Code and diversity measures (in criminal proceedings initiated against juveniles) etc. (Code of Criminal Procedure in Republic of Kosovo, no. 04/L-123).

\section{Code no. 04 / l-123 of the criminal procedure of the republic of kosovo}

It was said above that elements of restorative justice are also found in Code no. 04 / L123 of the criminal procedure of the Republic of Kosovo. These provisions of the Code of Criminal Procedure of the Republic of Kosovo are about alternative procedures, starting from: Temporary Suspension of the Procedure, conditions when the prosecution is not mandatory, mediation procedure - as one of the procedures in which most of the elements of restorative justice, plea bargaining, acquittal to cooperating witnesses are found.

\section{Mediation procedure}

Most elements of restorative justice are found in Article 232 of Code no. 04 / L-123 of the criminal procedure of the Republic of Kosovo, because according to the provisions of this 
article the state prosecutor may send a criminal report for a criminal offense punishable by a fine or imprisonment of up to three (3) years for mediation (Code of Criminal Procedure no.04/L-123). Before doing so, the state prosecutor takes into account the type and nature of the offense, the circumstances in which it was committed, the personality of the perpetrator and his previous convictions for the same offense or for different offenses, as well as the level of his criminal liability. Mediation is done by an independent mediator. The mediator is obliged to accept the case sent by the prosecutor and take measures to ensure that the content of the agreement is proportionate to the seriousness and consequences of the offense. The agreement can be reached through mediation only with the consent of the defendant and the injured party.

The provisions of the law above also apply to criminal matters and the parties (perpetrator and victim of the criminal offense) have their free will, unless otherwise provided by a special law. In the criminal field, mediation according to this law is applied in cases where a fine and imprisonment of up to three (3) years is provided, except in cases related to domestic violence under the Law against Domestic Violence or for any disputes for which the exclusive responsibility of the court or any other competent body is provided.

The mediation procedure according to this law is initiated by the parties, the court, the prosecution or the competent administrative body. In some civil cases (such as disputes from family relationships, etc.) mediation is mandatory. Whereas, in criminal cases mediation is optional. However, the parties themselves choose the mediator or co-mediator from the register of mediators licensed by the Ministry of Justice, who is obliged to inform the parties about the principles, rules, costs of the procedure and the legal effects of the agreement. According to this law, the mediation procedure starts at the moment when the parties sign the mediation agreement for the initiation of the mediation procedure. This procedure does not prevent the initiation or continuation of the court proceedings. The agreement for the mediated settlement depends on the will of the perpetrator and the victim. However, it is obligatory to deal with the issue that has been mediated.

\section{Negotiating a plea agreement}

In addition to the provisions of the articles mentioned above, elements of restorative justice are also found in Article 233 of Code no. 04 / L-123 of the criminal procedure of the Republic of Kosovo, because at any time before and after the filing of the indictment and before the end of the main trial, the state prosecutor and the defense counsel may negotiate the terms of the written plea agreement, based on the defendant and the state prosecutor agree on the 
charges contained in the indictment and the defendant agrees to plead guilty in exchange for the state prosecutor to recommend to the court a more lenient sentence, but not below the statutory minimum or the minimum defined in paragraph 7 of this Article or other considerations in the interest of justice, such as release from punishment under Article 234 of this Code. Even in this alternative procedure there are elements of restorative justice, because in such cases the defendant voluntarily enters into negotiations with the representative of the prosecution, not infrequently in the presence of the injured party, admits guilt, expresses readiness to repair the damage, etc.

\section{CONTEMPORARY PRACTICES OF RESTORATIVE JUSTICE}

From what has been said before about restorative justice in general and "restoration" as a term in particular, we can conclude that this term means nothing more than a "mechanism" for interpreting and managing and ending a social conflict. According to this finding, communication and action can also be called two essential elements of a restoration process because these are sending us on the path of understanding and agreement between the perpetrator on the one hand and the victim of crime on the other. Whereas the community should try to find out the reasons that sent the perpetrator to commit the crime, help him and the victim to reach an agreement through they will reach their full reconciliation and help the perpetrator in reintegration and prevent him from committing these kind of acts in the future.

Although contemporary restorative justice practices differ from one another, those differences are quite small, not to mention cosmetic, because their essence is the same and does not differ much from one to another restorative justice practice. We will see this in the following when we will talk separately about some of the practices of some of the contemporary states which we can freely call as states with a highly developed democracy and justice, especially in the field of restorative justice.

The practice of restorative justice in the US, the practices of restorative justice in the US are different, because it is a federal state, and each state has its own characteristics in the practice of restorative justice. In the state of Minnesota, USA, the Mediation Center was established and operational before 1985. The first cases, in this center, were sent for mediation in 1985, and that, at first, by the court of Minneapolis, and, then, also from that of Saint Paul, which was also the capital of Minnesota. Although this practice did not differ much from the general practices of restorative justice, it was distinguished by two tendencies. 
The first was to use a "non-directive" style, maximizing the willingness of the parties to formulate and present a remedial proposal, or, in other words, a compensatory one.

And, secondly, it had to do with serious crimes, for which they can turn to mediation. Restoration justice enforcement practices in this state do not recognize the objective limit. For this reason, in the literature on the practical application of this justice, it is stated that one of the main features of the Minnesota program is the use of mediation procedures, even in cases of conflict that have resulted in many crimes. This has been practiced in those cases where the victims themselves have thought reasonable to meet face to face with the perpetrator who committed the crime against them. Mediation in these cases is not considered as an opportunity for the perpetrator, but as an opportunity given to the victim to improve the feeling of anxiety and insecurity, respectively, the consequences of the act of violence, because, mediation, in these cases, it is more complex, because it is not only accompanied by the parties, but also by other persons, and, especially, by those who are providing medical assistance to the victims, starting from psychologists, psychiatrists, etc.

As in other legal systems, the legal system of this country pays attention to the mediator and his qualification. Probably, not for any other reason, but because of the tendency to perceive mediation as something different from the usual straightforwardness, as in many parts of the Anglo-Saxon system, because even this justice was influenced by these systems. In this system of justice, the mediator is said to be "voluntary" and "unprofessional", while the qualification is not mentioned as a condition for being a mediator, while, unlike this system, in the Euro-continental system, the mediator is told that he must be "professional" and specially prepared and qualified to perform this task.

In this country, research has been done to prove the effectiveness of the implementation of this justice, in practice. This research has shown that the victims of crime have been very satisfied with the results achieved through the practical application of restorative justice. While, dilemmas have emerged about the effectiveness of mediation because the data were controversial, because it had to be clarified whether the implementation of this justice should be considered effective, respecting every point of the agreement reached, or, it can be considered effective enforcement of this justice, even then an agreement was reached between the parties only on its main points. This research aimed to verify the correctness and equality of the agreements reached in the practice of applying this justice in this state. 
Unlike Minnesota, in Vermont, USA, this (restorative) justice is administered through the Probation Program. This program has been promoted by the Department of Corrections, Vermont. Looking at its content, this is a program through which the execution of the prison sentence is suspended, and the perpetrator is placed under probation.

With such measures, what is provided by the legislation of this state, as measures of restorative justice, do not replace the sentences of the perpetrators, but only suspend them for a while, to try the perpetrator.

Although part of this set of measures, the Vermont Probation Service Program differs from the traditional scheme. Through this instrument, it was sought to achieve a synthesis between the educational needs of the juvenile and the two basic goals of restorative justice, such as: Real protection of victims and greater involvement of the community in conflict resolution. In fact, it's exactly in the state of Vermont, that this aspect manages to be fully realized, if we take into account the fact that the community enters the "administration" of justice, with a decision-making and controlling function, always, within the guarantees of the criminal process.

The Reperative Probation Program in this state was born to administer moderate and low-risk juvenile delinquency cases (especially, referring to property crimes). In its structure, it fully corresponds to testing (with a probatin). After sentencing, the convict must report to the Community Repair Office, which consists of five or six citizens belonging to the community where the offense was committed. At the end of a series of meetings, an agreement is formalized, which includes the points of the restoration program that the culprit must follow in a time frame of 90 days. The Office, if it verifies the completion of the reparation process of the damage, asks the Court to decide on the dismissal of the case. Otherwise, the culprit will appear before the Criminal Court, for the purpose of applying punitive measures (Cerekja, 2013).

The practice of restorative justice in Germany, Mediation, in Germany, began to be applied in the late ' $80 \mathrm{~s}$, initially, in criminal proceedings against juveniles, and, later, in criminal proceedings against adults. At first there were difficulties in applying for the institute of mediation, but then it was facilitated thanks to the cooperation with juvenile courts, social workers, police forces and the entry into force of juvenile legislation, during 1990. With legal provisions of the legislation on juveniles, of 1990, mediation was equated with other educational measures, that can be imposed on the juvenile, because, in paragraph 1 of Article 
10 of the Juvenile Justice System, it was stated: "There are obligations and prohibitions that discipline the life of the juvenile and therefore favor / assist education. No liabilities can be foreseen that cannot be claimed from the point of view of the young person's life. In particular, the Judge may impose on the young person: 1. To comply with the orders related to the apartment; 2. To live near a family, or home; 3. Accept a designated job; 4. Perform a certain job; 5. To be subject to the treatment and supervision of a certain person (a certain assistant); 6. Participate in a social training course; 7. Strive to reach an agreement with the victim criminal mediation); 8. To leave meetings with certain persons and not to attend diverting places; 9. Participate in meetings where lectures on road education are given (Godesberg, 1998).

From point 7, paragraph 1 of article 10 of the Juvenile Rights System, you can see that this law has equated mediation with the educational measures mentioned above, because the legislator, in this case, through this legal provision, encourages the juvenile to reach a mediation agreement with the victim. The main purpose, according to the above-mentioned legal provisions, is not compensation, but the realization of the meeting in which the perpetrator and the victim should participate. From this, it can be seen that the German legislator intended to repair the damage caused by the criminal offense, by young people aged 14 to 21 years.

The juvenile prosecutor may waive the prosecution of the juvenile, the perpetrator of the criminal offense, if in the meantime educational measures have been taken (Dolling, 1998).

Another feature of juvenile criminal law in Germany is the possibility of ordering the mediator to mediate (Juvenile justice system, Article 10, paragraph 1 according to the German legislation of 1998, Bonn, Germany). This opportunity given to the court by law to order the offender to mediate has been rightly criticized by the authors. different, because such a possibility is also contrary to the principle that "the parties must participate in mediation, of their own free will." Apparently, this, in German practice, has been taken into account, because this order for mediation is given only when there is the will of the author of the criminal offense (Dunkel, 2002).

When it does not take place within the legal system, mediation, in Germany, is always carried out through social workers, or by the Juvenile Prosecutor. In many cases, the police also participate, selecting cases for treatment, taking some questionnaires, which, then, sends them to the competent bodies of the legal system and the juvenile prosecutor. 
In order to apply the mediation procedure in Germany, it is necessary to meet certain criteria, according to German practice. Among the most important are: Clear account of facts and circumstances; "Irrelevance" clause; The victim was personally injured; Existence of free will of the parties (perpetrator and victim).

A clear account of the facts, according to what has been said above, implies the basic principles of a fair legal process that, i.e., mediation, should never prejudice the rights to defend the defendant. Whereas with the clause of "irrelevance" it is understood that the mediation procedure can be applied only in those cases when at the end of the trial a decision of innocence cannot be given, with the motivation of "insignificance of the fact." The victim must have been personally injured in order for the mediation procedure to be carried out, according to German practice.

However, in order to implement the mediation procedure, according to the abovementioned practice of this state, it is necessary the existence of the free will of the parties (the perpetrator and the victim). This will be a bit dubious for the defendant, because he is obliged to undergo either the mediation procedure or the criminal procedure.

As part of the restoration law, in the beginning, this procedure (mediation procedure), even in German practice, was limited and applied only to perpetrators of minor offenses, or even some of the insignificant criminal offenses. In time it was seen that this did not make sense, therefore, the critics, criticized this. According to them, even crimes such as robbery and sexual crimes can be solved through mediation. According to them, the cases when the perpetrator is a recidivist should not be left out either From what has been said, you can see that damage repair policies have been widely accepted in Germany, thanks to the strong support of conservatives (who can be said to have become victims' spokespersons), but even the supporters of "criminal abolitionism", for whom, rightly, in various texts, it has been said that, they see mediation as the preferred means of supporting the theory of "privatization of conflicts" (Cerekja, 2013).

\section{Practice of implementation of restorative justice in Albania}

Even in the absence of an independent state and foreign invasions, historically the Albanian people did not live in anarchy and arbitrariness, but self-governed by the norms of customary law, where they found justice, which could not find in the laws of the invaders foreign. So, historically, the Albanian people have found "mediation for reconciliation" as an alternative to resolving disputes and conflicts (Gjeçovi, 1933). we talk and study the Albanian 
legislation in the field of mediation, because only in 1999, under the strong influence of the international factor, the Albanian legislator approved the law no. 8465, dated 11/03/1999 "On conflict resolution and settlement of disputes", which it turned out to be the cornerstone on which the "mediation wall" would be built, being institutionalized.

The influence of the internationals has been quite effective from the point of view of harmonization of domestic and international legislation during the transition years. This impetus has been very positive, because Albania now has one of the most advanced legislation in Europe and beyond in terms of the field of mediation, which from 1999 until now has had a rapid development and a fairly regulated good of this institute (Elezi, 2004).

According to the Albanian legislation in force, mediation in the criminal field is not obligatory, but when it is implemented, it consists in giving the parties to the conflict the opportunity to resolve it peacefully by cooperating responsibly with the mediator who has the obligation to the parties, to offer them a space to negotiate for less serious criminal offenses, such as: Bodily injuries, negligent injuries, etc. The legal regulation of the mediation procedure in Albania shows that Albania from 1999 onwards has been determined for the alternative settlement of disputes. In the beginning there were difficulties and obstacles in the application of this institute, but they were not insurmountable, because this institute continued to find application in resolving various conflicts and disputes in Albania, starting from family, then property and in the end even until the reconciliation of bloodshed. This finding is confirmed by the organization of the Central Commission for the Reconciliation of Bloodshed and that of the Foundation for Conflict Resolution and Dispute Resolution established in 1995. From what was said it can be seen that now in Albania the mediation institute has taken the proper form and that institutional because it is now regulated by a proper, organic and special law such as Law No. 10 385, dated 24.02.2011, "On mediation in resolving disputes", and by laws for its implementation, which is subject to the necessary changes and additions to avoid possible errors that were issued in the laws that had preceded this law. As in the theory of contemporary criminal law and the criminal laws of many democratic countries, in Albanian theory and practice alternative sentences are given special importance because these are proving more effective than imprisonment and their character is being seen that it is more democratic, educational, and quite humanitarian. Such a finding is confirmed by the Criminal Code of the Republic of Albania. Based on this, we can see that a special chapter which is devoted to alternative sentences as alternatives to imprisonment. However, this did not end there because in favor of this issue the norms in question became subject to changes and additions, with laws 
no. 10 023, dated 27.11.2008 and no. 144/2013, dated 02.05.2013, because these changes and additions were a result of the need for improvement and practical implementation of criminal policy, in order to encourage and rehabilitate the perpetrators of criminal offenses.

Albanian tradition, as well as the traditions of other nations and peoples, reminds us that the institution of reconciliation is deeply rooted in our lives and our good customs. Now, the time has come for this tradition to be raised to professional levels. The court, which has traditionally been recognized by all as the place where the state resolves the conflict, should increasingly be seen as a second alternative, as a last resort. In addition, other conflict resolution alternatives, such as mediation and arbitration, need to be strengthened. Mediation makes people simply better than they are, because it teaches them to love before they hate, it teaches them to forgive before they take revenge (Semini-Tutulani, 2012).

\section{ADVANTAGES AND REMARKS OF RESTORATIVE JUSTICE (RECONCILIATION PROGRAM)}

Of course, restorative justice as well as many institutes of criminal law have their advantages and disadvantages, in this case we can mention:

The advantages are impartiality during the implementation of the program; the most adequate height in compensation for damage; the mutual benefit of meetings between the victim and the perpetrator; admitting guilt by the perpetrator and repenting of the suffering caused to the victim; voltage reduction and mitigation; solving human and social problems and relationships. (Halili, 2011).

The remarks are: the fact that the reconciliation of the victim and the perpetrator is not always equivalent to imprisonment; the conciliation program has often dealt more with compensation than with the real reconciliation of the victim and the perpetrator; no precise data have been provided on whether the reconciliation program is equally appropriate for victims and perpetrators in serious cases of violence; it is considered that conciliation programs are not appropriate for cases of serious crimes and other remarks (Halili, 2011).

\section{THE VALUES THAT RESTORATIVE JUSTICE AIMS AT}

Although in criminal proceedings great importance is given to the perpetrator, restorative justice does not leave aside in the process neither the victim nor the community. The values that restorative justice seeks to achieve by the perpetrator include apology, shame for the act committed, and reintegration. Whereas, for the victim it is intended to correctly 
examine the damage caused to her and give justification by the offender. While for the community it is intended to restore the previous relationship.

The results and measures of the restorative justice program are based on the core values referred to by all three participants in this process. The perpetrator should address the victims in writing or orally and apologize to them and the community for his or her actions. He must learn to recognize his responsibility without seeing himself as a victim of circumstances and gaining knowledge of the evil he had committed. Reintegration means learning how to return to society through a treatment plan "curing" of an evil that has gripped you as a result of which you have broken the law and in that case the victim has been harmed and appreciate the damage suffered.The victim must accept an apology from the perpetrator and show that forgiveness. The values associated with the social community are directed towards repairing broken relationships and establishing new relationships within the community .

If we manage to make a comparison between retributive and restorative justice, we can say that: Retributive justice tries to create security in society, while restorative justice aims to establish peace in the community. Retributive justice is directed at separating unwanted people, like criminals, by imposing on them prison sentences, which is one of the most common types of criminal sanctions imposed by final convictions. Therefore, the opinion of most supporters of restorative justice is that the process of punishment has not yielded the desired results, because only those people who are on the verge of existence and who often conflict with the law because they are homeless, handicapped, poor citizens and members of minorities.

Creating peace in the community involves treating perpetrators who are part of the community because they will return to that community after incarceration. The community that deals directly with each individual refers to the family, friends and persons with whom the perpetrator is in a relationship, because these relationships provide an environment for the development of social awareness, awareness that one's actions affect other people and the desire for that person to improve and form a useful member of society (https://www.research.net/publication/287955358penalantropologhyfromretributivetowardsre stoartivejustice). 


\section{CONCLUSION}

From what was said, it can be seen and can be concluded that restorative justice for the object has the victim of the criminal offense, while the purpose is to restore the damage caused, reintegrate the perpetrator and the victim and restore harmony in the community through active participation, to repair the damage and reintegration of both the perpetrator and the victim, while traditional justice has as its object the criminal offense with the aim of punishing the perpetrator, because restorative justice understands and evaluates crime as an act by which the perpetrator harms other people, while traditional justice he understood the crime and now he understands it only as a violation of a legal norm.

For the traditional criminal justice system, it is important to know which laws have been violated in a particular case, who are the perpetrators of that or those violations and what punishment he or she deserves. Whereas, for restorative justice the most important thing is to know who is injured by the criminal offense committed, what are his / her needs and how this procedure will be carried out to be fulfilled those needs.

Restorative justice can take many forms have been found by many authors, but the one that can be found to be appropriate and the only one is the alternative form of action towards punishment which differs from the traditional one or better to say from the punitive form.

In order to be implemented properly this justice must be integrated as soon as possible in the existing criminal justice system and the conditions, standards and mechanisms through which it would be easier the implementation.

Providing clear conditions and standards for the implementation of restorative justice and placing it within the boundaries of the existing criminal justice system can help achieve restorative goals through the restorative process, without denying the possibility of achieving a restorative result through criminal proceedings.

Therefore, all states that today aspire to the genuine values of advanced societies are required to include in their existing criminal justice systems restorative justice as a form of state intervention based on its main elements, such as: Direct participation of parties to the conflict, as a "tool to facilitate harmonious social interactions" that lead to joint, inclusive decision-making, characterized by a bottom-up approach because, thus, the possibility of active involvement of all those affected by crime in the search for healing, repair increases of harm and relationships, concerned with crime, understanding, empathy, responsibility and 
prevention of future criminal behavior, since the conflict belongs to those involved in it, so they must resolve it through a participatory process, communication and dialogue.

Restoration processes also reflect other values of the restoration approach, such as: Respect, cooperation, empowerment, and volunteerism.

Everyone benefits from the implementation of restoration programs, starting from the victim, the perpetrator, the society but also the state itself, because through the application of these programs the negative impact of crime in society is reduced by providing compensation for the damage caused by crime, affecting reducing recidivism, engaging in order active in problem solving, creating a framework for ensuring and maintaining peace in the community and finally facilitating the criminal justice system to orient cases from classical criminal procedure to be resolved through restorative justice, thus sending us to strengthening informal social control mechanisms, resulting in minimizing the implementation of formal social control mechanisms, i.e.. mechanisms and institutions of the criminal justice system.

However, we must take into account the fact that even in the best reforms there are sometimes omissions, so in time they must be identified and kept under control so as not to dilute the good intention of those reforms.

Therefore, we must be careful even in cases of application of restorative justice, to begin to apply it to cases of lesser importance, and when it is shown that they are proving successful then, to begin to expand the circle of cases. in which it will be implemented but always with added care, studying all its effects, both positive and negative, and only then come to the conclusion of how and what should be regulated through this justice because, only in this way can the control of the process, the protection of all participants in the restoration procedure and the achievement of its goals be ensured.

Despite what was said and its very positive features, we must accept in this case the fact that the current legal solutions for the right of restoration in the Republic of Kosovo are more committed to the perpetrator and less to the victim, a fact that it should not be. Therefore, we must work to change this approach in the near future, so that at least both parties are equal as required by restorative justice and the readiness of the perpetrator to accept and fulfill certain obligations does not be greater than the readiness of the injured party to enter into a dialogue with the perpetrator of the criminal offense and his willingness to accept the compensation offered, for the sake of an efficiency of the procedure, because it would be contrary to the 
greater need of restorative justice to protect the interests of the parties to the conflict and especially the injured party to the criminal offense.

We cannot say that in Kosovo everything has been achieved in terms of the application of restorative justice, but we can boast that in a short time it has been achieved that many laws are changed and harmonized with international law and many conflicts between the parties to be resolved no longer through the traditional criminal way but alternatively, with the consent of both parties where the damage was compensated, the parties were brought closer and the perpetrator was given the opportunity to become aware and integrate into society.

This is the best indicator that restorative justice is one of the best forms of crime response. Although opinions on this type of justice (restorative justice) are very good and hopeful, in theory we encounter different opinions regarding the possibilities for the implementation of this justice in practice. Therefore, the competent authorities should be informed about the lack of those mechanisms and the need to build them, because it is not enough just to build legal mechanisms without competent institutions that help, facilitate and enable the efficient implementation of this justice in practice. In this way it would also contribute to the advancement of this justice in relation to traditional criminal justice.

Our legislator has limited the application of this justice only to minor criminal cases, excluding in this case the conflicts related to domestic violence and some others that are expressly provided by law because it is based on the practices of some other states that have hesitated and have not trusted enough in this justice. However, despite all the current legal and institutional mechanisms, we cannot say that they are enough, because this is still a new field and after a while it can be seen that there is a need for new legal and institutional mechanisms for fair implementation, fast, at the lowest cost by achieving its reparative as well as noble as its purpose of achieving peace between the perpetrator and the injured party himself. Therefore, those mechanisms that would appear to be necessary would need to be immediately built and put in place to implement restorative justice properly and adequately.

What was said makes us understand that there is still a need for coordination and consolidation of the actions of entities and bodies dealing with the implementation of this justice and rules through which a clear system of action would be established which could contribute to the frequent implementation of restoration models by harmonizing, standardizing and systematically clarifying the practices of practical implementation of restorative justice in Kosovo. What has been said about this justice so far is not as important as it is important that 
in the future it is necessary to take a series of concrete steps to further develop and improve restorative justice in Kosovo, but even wider if not for another then for the fact that restorative justice for the object has the victim of the criminal offense, while for the purpose of restoring the damage caused, whereas traditional justice for the object has the criminal offense, while for the purpose of punishing the perpetrator. 


\section{REFERENCES}

Adzajlic-Dedovic, A. (2007). Restorative Justice, translated into Albanian by Prof. Mustafa Reçica, page.105-106.

Braithwaite, J. (2002) Restorative Justice\&Responsive Regulation, page.249.

Cerekja, B. (2013). Mediation in Juvenile Offenses, page.52.

Code of Criminal Procedure in the Republic of Kosovo, 04 / L-123 / 28.12.2012.

Criminal Code of the Republic of Albania, no. 10 023, dated 27.11.2008 and no. 144/2013, dated 02.05.2013.

Criminal Code of the Republic of Kosovo, 06 / L-074 / 14.01.2019.

Dolling, D. (1998) Juvenile Justice System, article 10 paragraph 1.

Dunkel, F. (2002) The Mediation in Germany, page.120-121.

Elezi, I. (2004) Mediation for Reconciliation in Criminal Conflicts, page.145.

Gjeçovi, Sh. (1933) Canon of Lekë Dukagjini, page.35.

Halili, R. (2011) Viktimology, page.170.

https://www.research.net/publication/287955358penalantropologhyfromretributivetowardsres toartivejustice)

Juvenile justice system, Article 10, paragraph 1 according to the German legislation of 1998, Bonn, Germany

Krasniqi, E. (2015) Roman Law (introduction), page.54-55 and 64.

Law on Mediation in the Republic of Albania, No. 10 385, dated 24.02.2011.

Semini-Tutulani, M. (2012) Commentary on the Law on Mediation in Resolving Disputes, No.10835.

Tulumovic, M. (2014) Restorative Justice, page.635.

Van Ness, D. (2014) Restoring Justice/ An introduction to Restorative Justice.

Weitekamp, E. (1999). The history of restorative Justice, page.75-102. 